\title{
Tatlısu Levreği (Perca fluviatilis L., 1758)'nin Yaş Tayininde Kullanılan Omur ve Otolit Yöntemlerinin Karşılaştırılması
}

\author{
Canan İMAMOĞLU ${ }^{*}$, Nazmi POLAT ${ }^{2}$, Semra SAYGIN $^{3}$, Melek ÖZPIÇAK ${ }^{4}$, Savaş YILMAZ
}

\begin{abstract}
$\ddot{\mathbf{O} z}$
Bu çalışmada, Yedikır Baraj Gölü (YBG)'nde yaşayan Tatlısu Levreği (Perca fluviatilis L., 1758)'nin yaş tayininde kullanılan omur ve otolit yöntemlerinin karşılaştırmalı analizinin yapılarak, yaş tayini için ideal yöntemin belirlenmesi amaçlanmıştır. Örnekler Aralık 2015 ve Nisan 2017 tarihleri arasında Yedikır Baraj Gölü’nden yakalanmıştır. Yaş tayini için 235 örnekten omur ve otolit alınmıș, ayrıca seçilen 65 örneğe ait otolitler kesit alma tekniğine tabi tutulmuştur. Omur, bütün otolit ve kesit alınmış otolitte bir okuyucu tarafından 3 tekrarlı yaş okuması gerçekleştirilmiştir. Yaş tayini uyumunun tespit edilmesinde yüzde uyum (YU), ortalama yüzde hata $(\mathrm{OYH})$ ve değişim katsayısı (DK) kullanılmıştır. Populasyon genelinde yaş dağılımı 0-5 yaş olarak gözlenmiştir. Baskın yaş sınıfı omur (\%61.70), bütün otolit (\%61.25) ve kesit otolit (\%43.08) için 0 (sıfır) olarak hesaplanmıştır. Omur ve otolit yöntemleri karşılaştırıldığında en yüksek yüzde uyum \%84.69 ile otolitte tespit edilmiştir. Bütün otolit-omur, bütün otolit-kesit alınmış otolit ve kesit alınmış otolit-omur yaşları karşılaştırıldığında, en yüksek yüzde uyumun bütün otolit ve kesit alınmış otolit arasında olduğu saptanmıştır (\%78.5). Perca fluviatilis'in YBG populasyonunda yaş tayini için otolitlerin omura göre daha iyi sonuç verdiği tespit edilmiştir. Bütün otolit ve kesit otolit yöntemlerinden birinin tercih edilmesi gerektiği durumlarda ise bütün otolitin kullanılabileceği sonucuna ulaşılmıştır.
\end{abstract}

Anahtar kelimeler: Perca fluviatilis, yedikır baraj gölü, yaş tayini, omur, otolit

\section{Comparison of Vertebra and Otolith Methods Used in Age Determination of European Perch (Perca fluviatilis L., 1758)}

\begin{abstract}
In this study, it was aimed to detect the ideal age determination method by making comparative analyzes of vertebrae and otolith used in age determination of European Perch (Perca fluviatilis L., 1758) living in Yedikır Dam Lake (YDL). Individuals were caught from YDL between December 2015 and April 2017. Vertebrae and otoliths were taken from 235 samples for age determination, and otoliths from 65 selected samples were subjected to sectioning technique. A triplicate reading of the vertebra, whole otoliths, and cross-sectioned otoliths was performed by one reader. Percent agreement, avarage percent error and coefficient of variation were used to ageing precision. The age distribution of the population in general was 0-5 years. The dominant age class was 0 (zero) for vertebra (61.70\%), whole otolith (61.25\%) and sectioned otolith $(43.08 \%)$. When the vertebral and otolith methods were compared, the highest percent agreement (PA) was determined for otolith with $84.69 \%$. When whole otolith-vertebrae, whole otolith-sectioned otoliths and cross-sectioned otolith-vertebral ages were compared, the highest PA was found between whole and sectioned otoliths (78.5\%). It has been determined that otoliths give better results than vertebra for age determination of Perca fluviatilis in the YBG population. It has been concluded that whole otoliths can be used when one of the otolith and sectioned-otolith methods should be preferred.
\end{abstract}

Keywords: Perca fluviatilis, yedikır dam lake, age determination, vertebra, otolith

\footnotetext{
1,2,3,4,5 Ondokuz Mayıs Üniversitesi, Fen-Edebiyat Fakültesi, Biyoloji Bölümü, Samsun, Türkiye, canansimsekimamoglu@gmail.com npolat@omu.edu.tr semra.saygin@omu.edu.tr melek.zengin@omu.edu.tr savas.yilmaz@omu.edu.tr
} 


\section{Giriş}

Balıkçılık biyolojisinde kullanılan en önemli değişkenlerden biri yaş bilgisidir (Tyler ve ark., 1989). Yaş verileri balıklarda populasyon çalışmalarında tercih edilen en önemli yöntemlerdendir. Balıkların yaşam süresinin doğru olarak bilinmesi yaş ve ekolojik faktörler arasındaki ilişkinin anlaşılması için büyük bir önem arz etmektedir (Das, 1994). Balık stoklarının ve balıkçılığın uygun yönetimi için, populasyonların spesifik yaş yapısı ve gelişme oranlarının bilinmesi gerekir. Kemiksi yapılar üzerinde yer alan yıllık büyüme halkaları, araştırıcıların yaşı tespit edebilmelerine olanak sağlamıştır. Yaş verileri, boy ve ağırlık ölçümleriyle ilgili yaş değerleri, stok kompozisyonu, ilk cinsi olgunluk yaşı, üreme ömrü, büyüme, ölüm ve ürün miktarı ile ilgili bilgiler vermektedir (Karataş, 2010).

Balıklarda kemiksi yapılarda (omur, otolit, yüzgeç ışını gibi) yaş okuma, halka karakterlerinin durumuna göre farklı tekniklerle gerçekleştirilebilmektedir. Kemiksi yapılarda merkez bölgesi ve ilk yaş halkasının tespit edilememesi, yalancı halka varlığı söz konusu olduğunda kesit alma tekniği uygulanabilmektedir. Bu yöntem özellikle büyük örneklerde kalsiyum birikiminden dolayı daha sağlıklı sonuçlar verebilmektedir (Dwyer, 2003; Ceyhan ve Akyol, 2006; Yılmaz, 2006).

Tatlısu Levreği, Perca fluviatilis L., 1758 Percidae familyasına ait bir balık türüdür. P. fluviatilis Avrupa ve Asya'da dağılım göstermektedir. Tür, hem ticari hem de spor balıkçılığı için önem arz etmektedir ve doğal dağılım alanları dışında, Güney Afrika, Avustralya ve Yeni Zelanda'da bulunmaktadır (Thorpe, 1977; Craig, 2000).

Bu çalışmanın amacını; Yedikır Baraj Gölü’nde yaşayan Tatlısu Levreği’nin yaş tayini için kullanılan omur ve otolit yöntemlerinin karşılaştırmalı analizlerinin gerçekleştirilmesi oluşturmaktadır.

\section{Materyal ve Metot}

Araştırma alanımız olan Yedikır Barajı (Yedikuğular Kuş Cenneti), Amasya'da Tersakan Çayı üzerinde yaklaşık 1000 hektarlık bir alana DSİ tarafından sulama amacıyla 1982-1985 yılları arasında inşa edilmiş bir barajdır (Anonim, 2018). Baraj gölünü besleyen tek akarsu olan Tersakan Çayı Ladik Gölü’nden doğmaktadır. Fındıcak, Hamamayağı, Havza ve Derinöz kollarıyla Suluova'ya girerek, Amasya şehrinin 1-2 km çıkışında Yeşilırmak'a karışmaktadır (Maraşlıoğlu, 2007; Anonim, 2018; Şekil 1). 


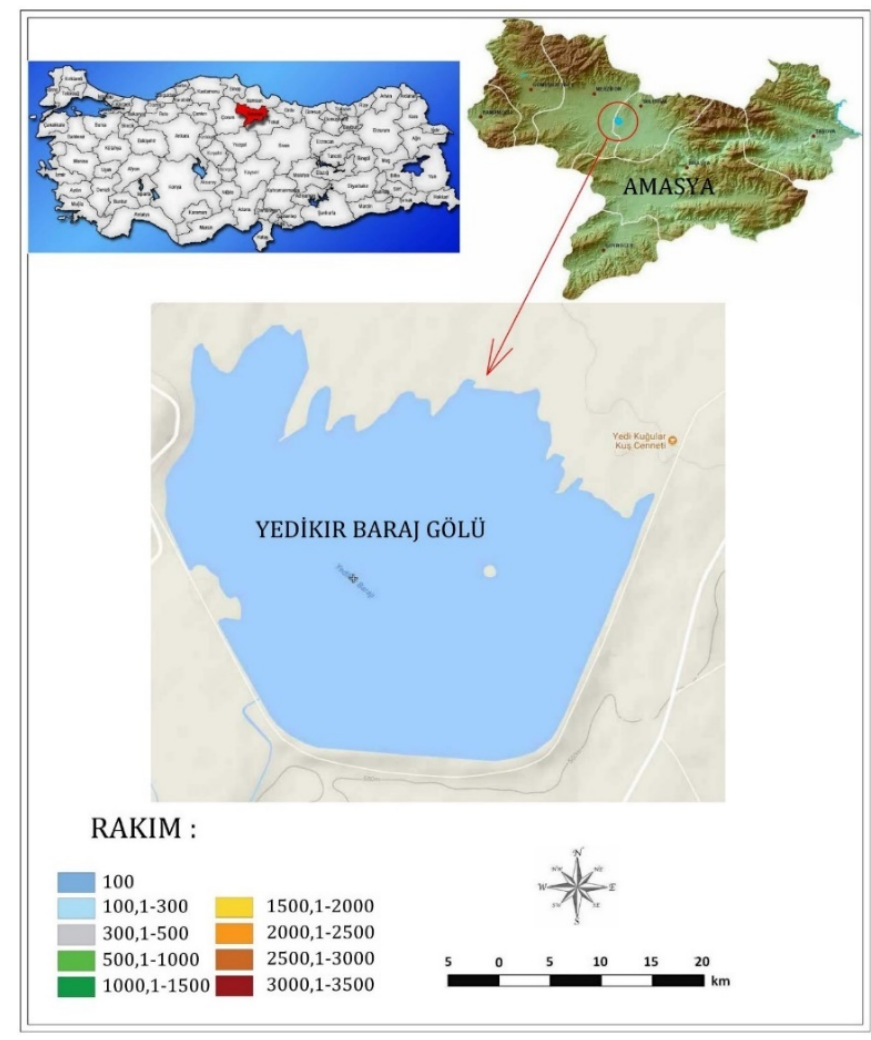

Şekil 1. Araştırma alanı haritası

Örnekler (N=235) Aralık 2015-Nisan 2017 tarihleri arasında Yedikır Barajı'ndan belirlenen istasyondan (4047'10.80"K ve 35 33'50.67"D) yakalanmıştır (Şekil 1). Örnekleme sırasında SAMUS 725MP marka elektroşok cihazı kullanılmıştır. Yakalanan örneklerin total, çatal ve standart boyları $( \pm 0.1 \mathrm{~cm})$ ölçülmüş ve ağırlıkları tartılmıştır $( \pm 0.01 \mathrm{~g})$. Literatür incelendiğinde türün yaş tayini için en ideal kemiksi yapıların omurlar ve otolitler olduğu gözlenmiştir (Saygın, 2013; Banda, 2014). Bu sebeple, çalışmada yaş tayini için örneklerden omurlar ve sagittal otolitler alınarak değerlendirilmiştir. Ayrıca seçilen 65 örneğe ait otolitler kesit alma tekniğine tabi tutulmuştur. Otolitten kesit alma tekniğinin gerçekleştirilebilmesi için otolit örnekleri polyester karışımdan oluşan plastik kalıplara gömme işlemine tabi tutulmuştur.

Polyester karışımdan oluşan kalıp içindeki merkezi belirlenen otolit Buehler Isomet Low Speed Saw marka kesit alma cihazına düzgün bir şekilde yerleştirilmiştir ve 0.30-0.35 mm kalınlığında enine (transversal) kesitler alınmıştır (Şekil 2). Kesit alınan örnek her iki yüzeyden olacak şekilde zımparalama işlemine tabi tutulmuştur. Zımparalama işlemi için 400 grid, 800 grid ve 1200 gridlik zımparalar kullanılmıştır (Secor ve ark., 1992). Zımparalanan örnekler ksilolde temizlendikten sonra lam üzerine konulup entellan eklenerek lamel ile kapatılıp preperat haline getirilmiştir. 

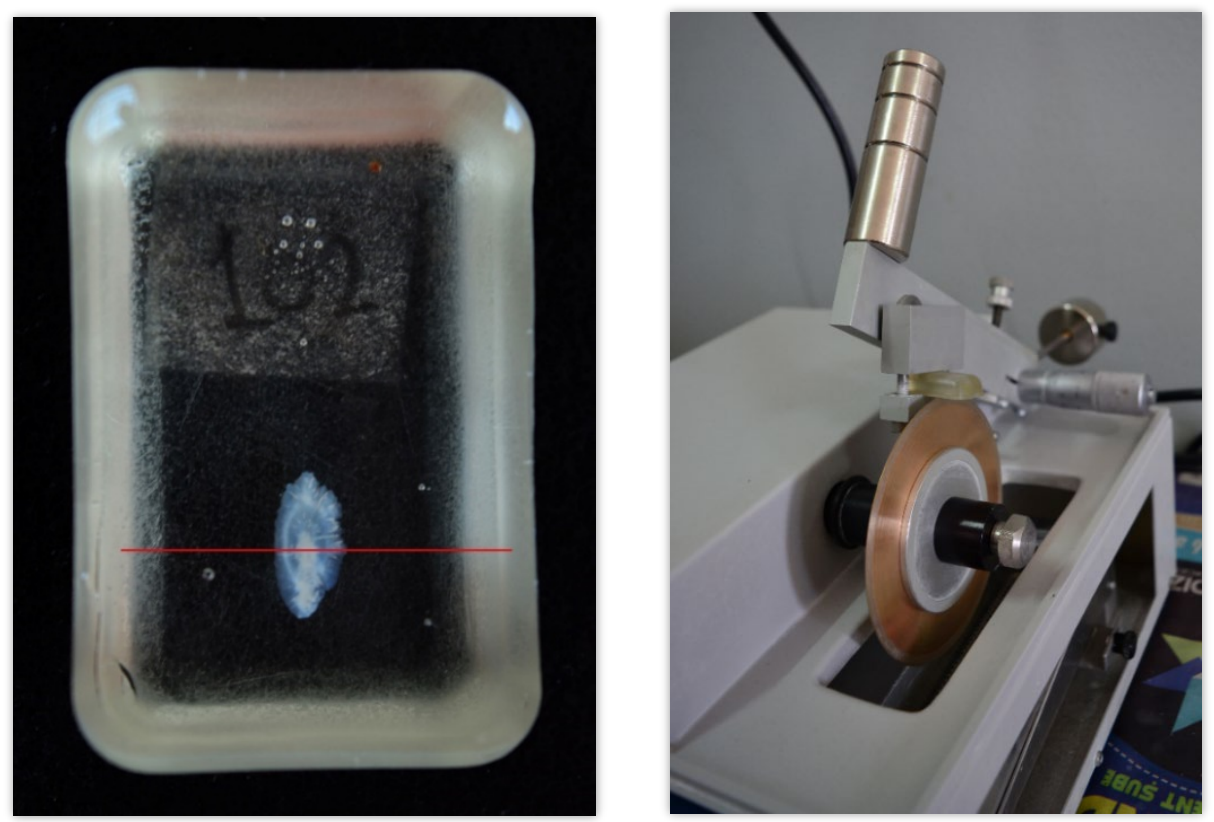

Şekil 2. (a) Kesit alma tekniği için hazırlanmış olan otolit preparatı (b) Kesit alma cihazına yerleştirilmiş otolit örneği

Otolitten yaş tayini için 2 farklı yöntem kullanılmıştır. Bu yöntemlerden biri bütün otolit örneğinin distal yüzeyinden yaş okunması, diğeri ise otolitten transversal kesit alınarak yaş okunması şeklindedir. Yaş tayininin gerçekleştirilmesi için seçilmiş olan her bir omur örneğinden de yüzeyden okuma yapılmıştır.

Her bir kemiksi yap1 (bütün otolit, kesit otolit ve omur) örneğinin yaşı binoküler mikroskopta bir okuyucu tarafından farklı zamanlarda $3 \mathrm{kez}$ okunmuştur. Tekrarlı yaş okumalarının analizi için ortalama yaş (Baker ve Timmons, 1991), yaşlardaki doğruluk, yüzde uyum, ortalama yüzde hata (Beamish ve Fournier, 1981) ve değişim katsayısı (Chang, 1982) belirlenmiştir. Omur-bütün otolit, bütün otolit-kesit alınmış otolit ve kesit alınmış otolit-omur yaşları arasındaki uyum karşılaştırılarak değerlendirilmiştir.

\section{Bulgular ve Tartışma}

Yakalanan örneklerin minimum ve maksimum boyları 4.6-24.0 cm ve ağırlıkları 0.98-210.22 g arasında değişmektedir. Bütün otolit, kesit otolit ve omurlardan 3 tekrarlı okuma sonucunda farklı yaş dağılımları elde edilmiştir.

P. fluviatilis'in küçük yaş örneklerin okunması sırasında bütün sagittal otolitlerde okuma zorluğu olmazken 4 yaşından büyük olan bireylerde ise merkez kısmındaki kalınlaşma ve kenar kısmında yoğunlaşan halka karakterleri sebebiyle okuma zorluğu yaşanmıştır. Yüzeyden okumanın zor olduğu sagittal otolitlerde kesit tekniği uygulanmıştır. Literatürler incelendiğinde, $P$. fluviatilis türünün yaşının belirlenmesinde otolitlerin kullanıldığı birçok çalışma mevcuttur (Linkøkken ve ark., 
1991; Linløkken ve Seeland, 1996; Sarvala ve Helminen, 1996; Holmgren ve Appelberg, 2001; Beğburs, 2010; Olin ve ark., 2010; Troynikov ve ark., 2011; Saygın, 2013; Banda, 2014; Saygın ve ark., 2015).

Balıklarda mevcut omurların tümü aynı halka özelliği göstermediğinden genellikle belirli bir bölgeden alınmış ya da seçilmiş omurlar tercih edilmektedir. Bu çalışmada 4-10. omurlar yaş belirleme amacıyla alınmıştır. Omurlarda yaş okuma esnasında ilk yaş halkasının tespiti dikkat edilmesi gereken noktaların başında gelmektedir.

Türün yaş okumasında elverişli olan 2 kemiksi yapısından 3 tekrarlı okumalar neticesinde 0-5 arası yaşlar gözlenmiştir. En yüksek yaş omurda 5, bütün otolitte 5 ve kesit alınmış otolitte 4 olarak belirlenmiş ve tüm yapılarda 0 yaş grubu baskın yıl sınıfı olarak saptanmıştır (Şekil 3). Kemiksi yapılarda gözlenen yaş grupları ile bu gruplardaki birey sayıları ve yüzdeleri Tablo 1'de gösterilmiştir. Ayrıca kemiksi yapılardan çekilen fotoğraflar Şekil 4, 5, 6’ da sunulmuştur.

Tablo 1. Yedikır Baraj Gölü’nde yaşayan P. fluviatilis örnekleminin yaş gruplarına göre birey sayıları ve yüzdeleri

\begin{tabular}{|c|c|c|c|c|c|c|c|c|}
\hline \multirow[t]{2}{*}{ Kemiksi Yapı } & & \multicolumn{6}{|c|}{ Yaş Grupları } & \multirow[t]{2}{*}{ Toplam } \\
\hline & & $\mathbf{0}$ & 1 & 2 & 3 & 4 & 5 & \\
\hline \multirow{2}{*}{ Omur } & $\mathbf{N}$ & 145 & 38 & 32 & 7 & 8 & 5 & 235 \\
\hline & $\%$ & 61.70 & 16.17 & 13.62 & 2.98 & 3.40 & 2.13 & 100 \\
\hline \multirow{2}{*}{ Bütün otolit } & $\mathbf{N}$ & 144 & 46 & 32 & 10 & 2 & 1 & 235 \\
\hline & $\%$ & 61.28 & 19.57 & 13.62 & 4.26 & 0.85 & 0.42 & 100 \\
\hline \multirow{2}{*}{ Kesit otolit } & $\mathbf{N}$ & 28 & 14 & 17 & 4 & 2 & - & 65 \\
\hline & $\%$ & 43.08 & 21.54 & 26.15 & 6.15 & 3.08 & - & 100 \\
\hline
\end{tabular}
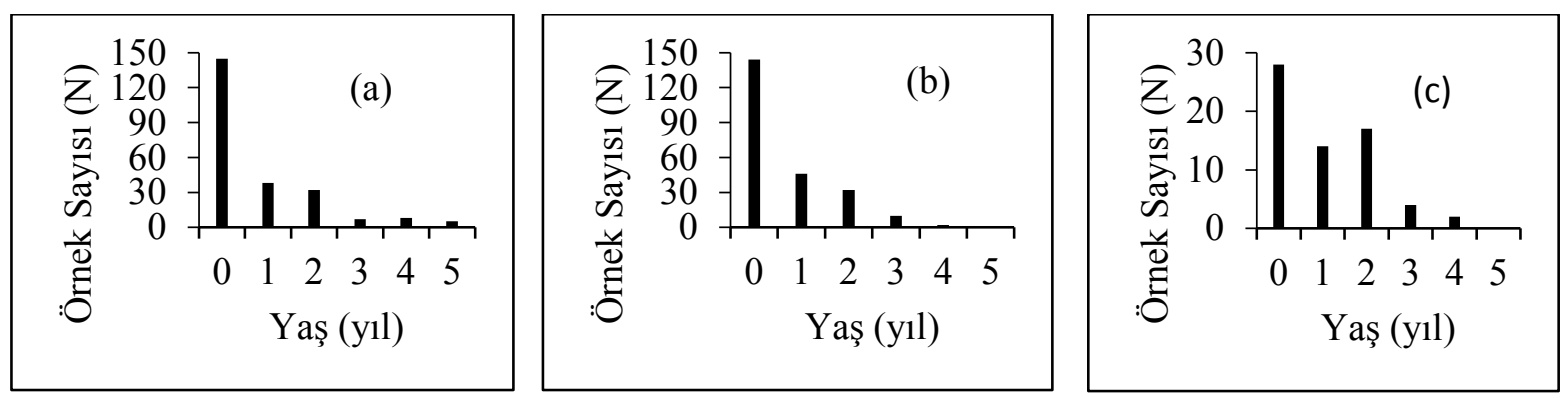

Şekil 3. Kemiksi yapılardan elde edilen yaş dağılımı (a: Omur, b: Bütün otolit, c: Kesit otolit)

Kemiksi yapılarda ortalama yaş hesabı, yapının güvenirliliğini belirlememekle birlikte normalin altında ya da üstünde yaş tayini yapıldığg konusunda bilgiler verebilir (Polat ve ark., 2004). Ortalama yaşlar omur, bütün otolit ve kesit otolitte sırasıyla 0.7220, 0.6440, 1.092 olarak hesaplanmıştır. Yaşların değişim aralığı 0.448 olarak belirlenmiştir. Ortalama yaşın değişim aralığ bütün otolit, kesit otolit ve omur arasında 1 yıldan daha az bir yaş farkının olduğunu göstermiştir. Bu 
çalışmada omur ile yüzey otolit okumalarının birbirine yakın çıkması okuma kriterlerinin benzer olduğuna işaret etmektedir.

Yüzde uyum tek başına ideal kemiksi yapının kullanımını belirleyemez ama uyumun yüksek olması da güvenilir yöntemin tercihi için önemli bir kriterdir. Yaş verilerinin analizinde dikkate alınan ilk adım olan yüzde uyum değerleri incelendiğinde; tekrarlı okumalarda \%100 uyumun olduğu örnek yüzdesi (\%84.6) ve hiçbir uyumun olmadığı örnek yüzdesi (\%2.55) bütün otolit için daha yüksektir. Ayrıca tekrarlı 3 okumanın da farklı olduğu örnek sayısının yüzdesi kesit otolit için en küçük değerdedir (Tablo 2).

Tablo 2. Kemiksi oluşumlarda yüzde uyum değerleri $(\% \mathrm{~N})$ ve birey sayıları $(\mathrm{N})$

\begin{tabular}{cccccc}
\hline Kemiksi Yapı & \multicolumn{3}{c}{ Uyum Gruplar } & Toplam \\
\hline & & $\mathbf{3 / 3}$ & $\mathbf{2 / 3}$ & $\mathbf{1 / 3}$ & \\
Omur & $\mathbf{\%}$ & 83.83 & 14.47 & 1.70 & 100 \\
& $\mathbf{N}$ & 197 & 34 & 4 & 235 \\
\multirow{2}{*}{ Bütün otolit } & $\mathbf{\%} \mathbf{N}$ & 84.69 & 12.76 & 2.55 & 100 \\
& $\mathbf{N}$ & 199 & 30 & 6 & 235 \\
Kesit otolit & $\mathbf{\%} \mathbf{N}$ & 72.30 & 27.70 & 0 & 100 \\
& $\mathbf{N}$ & 47 & 18 & 0 & 65 \\
\hline
\end{tabular}

Ortalama yüzde hata ve değişim katsayısı yaş tayini hata değerinin belirlenmesinde kullanılan iki önemli bağıntıdır. OYH ve DK ne kadar küçük tespit edilirse ilgili yapıda okumaların güvenirliliği o derecede artmaktadır. OYH ve DK sonuçları değerlendirildiğinde ise kesit otolitin daha güvenilir sonuçlar verdiğine işaret etmektedir. En düşük OYH ve DK değerleri kesit otolit için elde edilmiştir. $\mathrm{Bu}$ sonuç kesit otolitteki tekrarlı okumaların diğer kemiksi yapılara daha tutarlı olduğunu ifade etmektedir. OYH ve DK'nin küçükten büyüğe doğru sıralanışı kesit otolit $<$ bütün otolit< $<$ omur şeklindedir (Tablo 3). Bu ortaya çıkan farkın nedeninin kesit otolit örnek sayısının az olmasından kaynaklandığı düşünülmektedir. Saygın ve ark. (2015), Ladik Gölü’nde yaşayan türün 5 farklı kemiksi yapısında karşılaştırmalı yaş tayini çalışmasında en yüksek uyum \%77.19 ile omur örneklerinde tespit etmişlerdir.

Tablo 3. Kemiksi oluşumlarda OYH ve DK değerleri

\begin{tabular}{cccc}
\hline Kemiksi Yapı & $\begin{array}{c}\text { Örnek Sayısı } \\
(\mathbf{N})\end{array}$ & $\begin{array}{c}\text { Ortalama Yüzde Hata } \\
(\mathbf{O Y H} \pm \text { Sh) }\end{array}$ & $\begin{array}{c}\text { Değişim Katsayısı } \\
(\mathbf{D K} \pm \text { Sh })\end{array}$ \\
\hline Omur & 65 & $15.73 \pm 3.87$ & $20.82 \pm 5.06$ \\
Bütün otolit & 65 & $13.98 \pm 2.93$ & $18.55 \pm 3.88$ \\
Kesit otolit & 65 & $9.51 \pm 2.20$ & $12.35 \pm 2.85$ \\
\hline
\end{tabular}




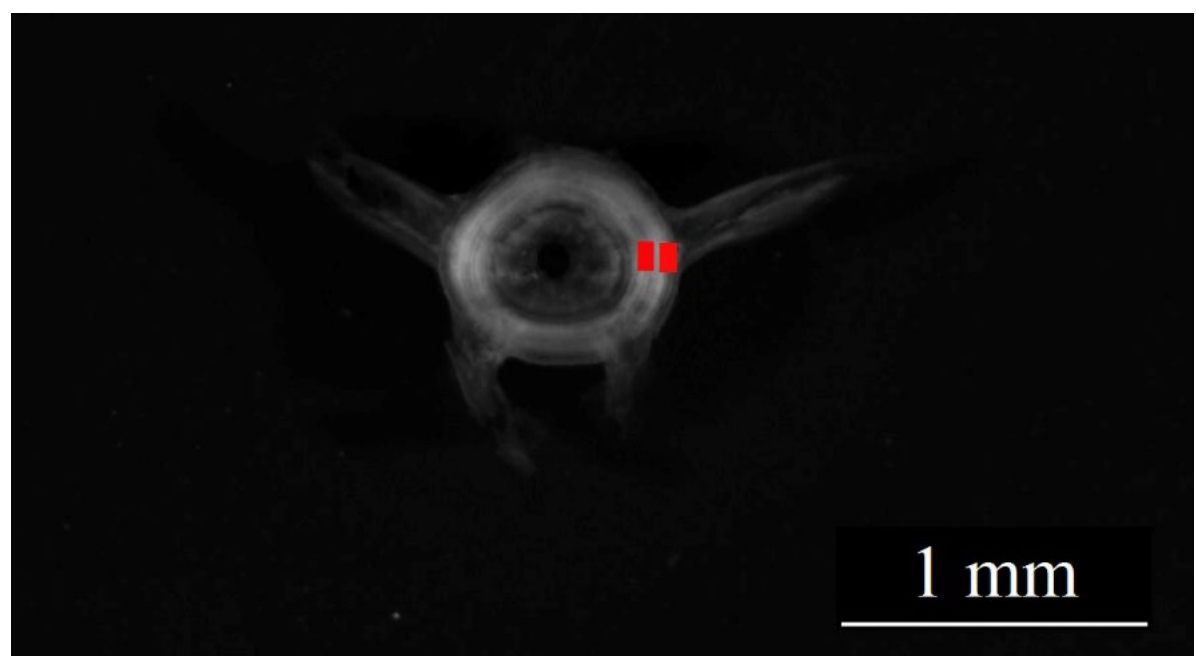

Şekil 4. P. fluviatilis omuru, 1+ yaş

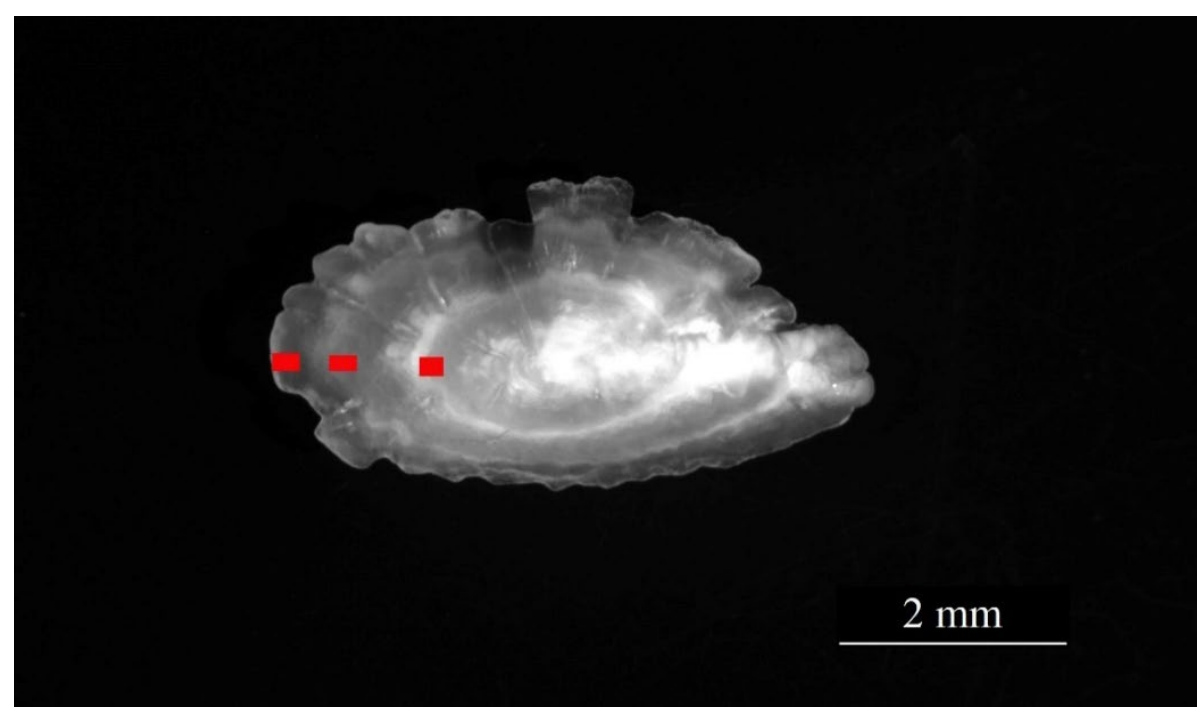

Şekil 5. $P$. fluviatilis bütün otoliti, 2(3) yaş

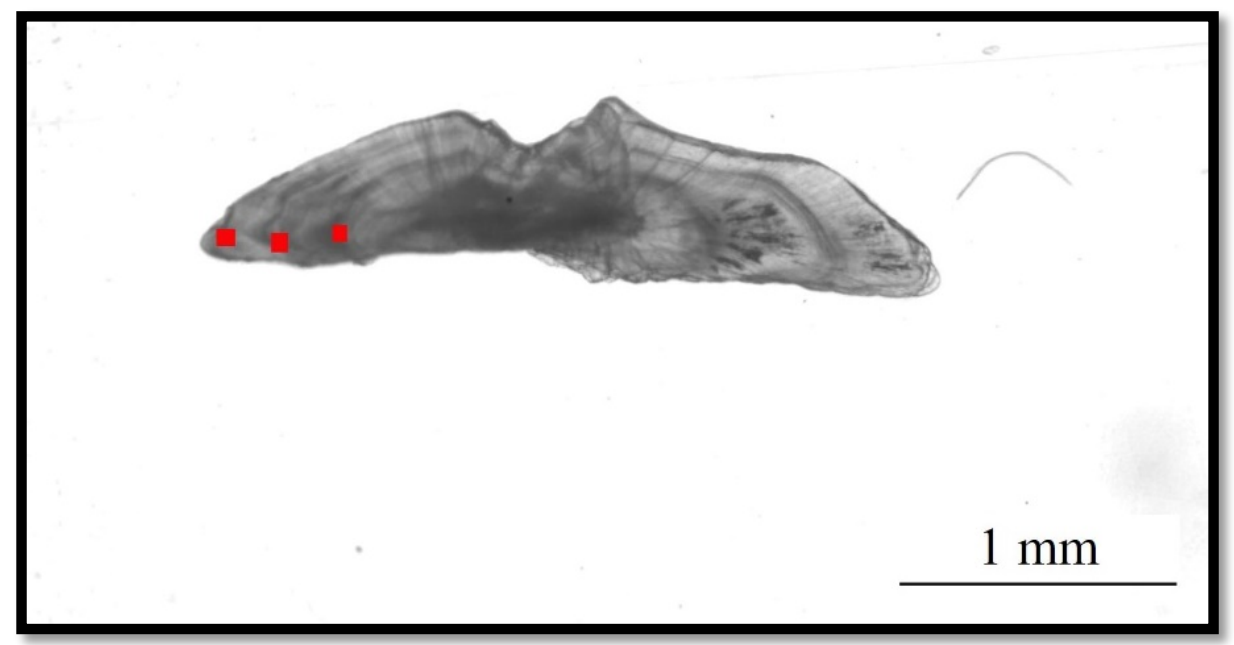

Şekil 6. P. fluviatilis kesit otoliti, 2(3) yaş 
Kemiksi yapıların karşılaştırılması Şekil 7, 8 ve 9'da gösterilmiştir. Bütün otolit-omur, bütün otolit-kesit otolit ve kesit otolit-omur yaşları YU verileri karşılaştırıldığında en yüksek uyumun bütün otolit ve kesit otolit (\%78.5) arasında olduğu tespit edilmiştir.

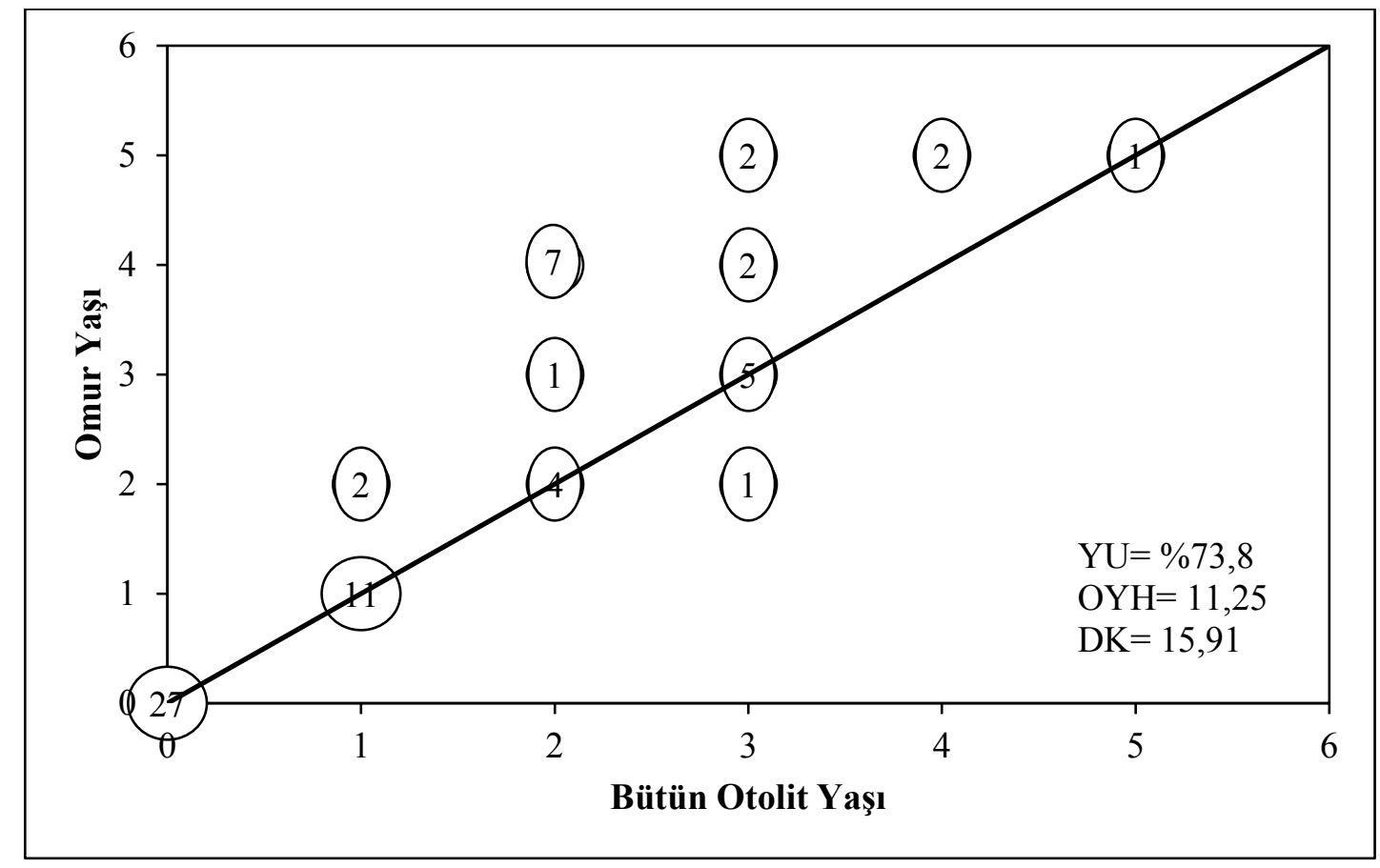

Şekil 7. P. fluviatilis örnekleminde bütün otolit yaşları ile omur yaşlarının karşılaştırılması

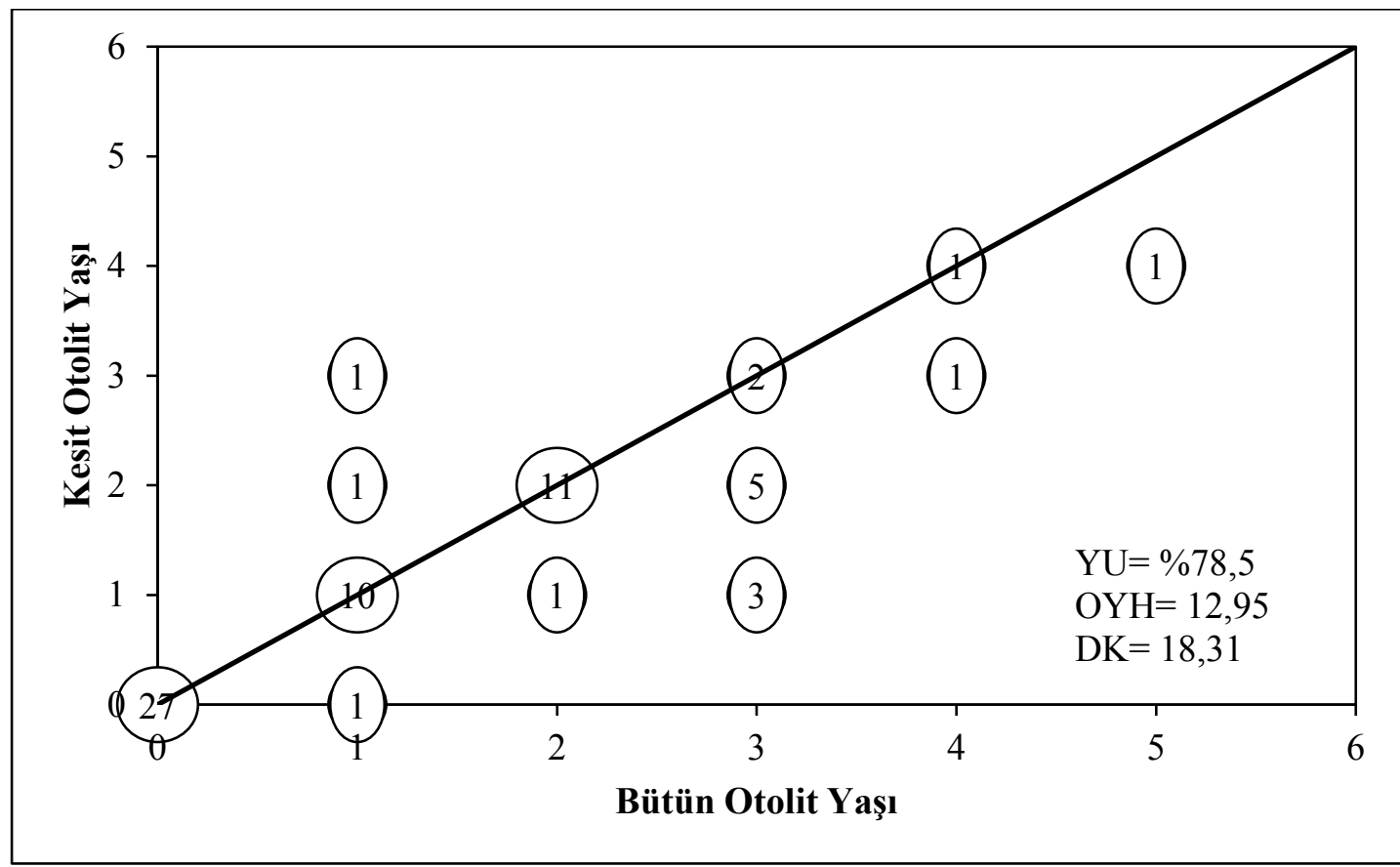

Şekil 8. P. fluviatilis örnekleminde bütün otolit yaşları ile kesit otolit yaşlarının karşılaştırılması 


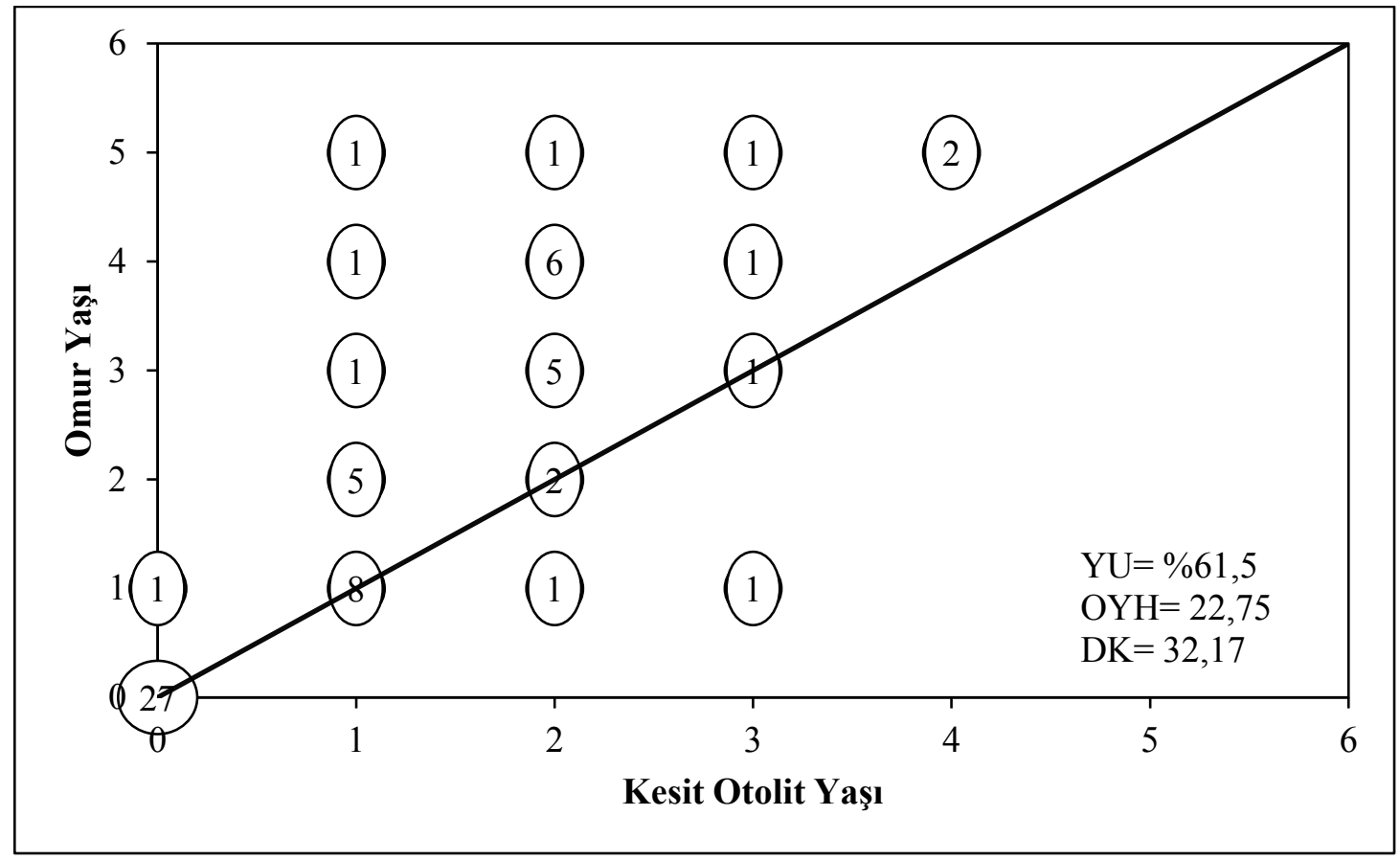

Şekil 9. P. fluviatilis örnekleminde kesit otolit yaşları ile omur yaşlarının karşılaştırılması

Gerekli analizler ile bütün otolit ve kesit otolitten elde edilen veriler incelendiğinde bütün otolit ve kesit otolit sonuçları arasında fark olmadığı sonucuna varılmıştır. Bu sonucun elde edilmesinin sebebinin türe ait büyük yaş örneklerin sayısının az olmasından kaynakladığı düşünülmektedir. Çünkü balığın yaşı arttıkça otolit ve omur örneklerinde yaş okuma zorlaşmaktadır. Tür ile ilgili daha önce yapılan çalışmalar dikkate alındığında örneklerin yaş dağılımının bu çalışmaya göre daha geniş bir aralıkta olduğu görülmüştür (Jellyman, 1980; Beğburs, 2010; Heibo ve Magnhagen, 2005; Ceccuzzi ve ark., 2011; Jatmico, 2013; Saygın, 2013; Banda, 2014; Saygın ve ark., 2015). Saygın ve ark. (2015), Ladik Gölü’nde yaşayan türün omur ve bütün otolit örnekleri karşılaştırıldığında yüzde uyum değeri \%51.75 olarak hesaplamışlardır.

\section{Sonuçlar ve Öneriler}

Perca fluviatilis türünde yaş belirleme için otolitlerin omura göre daha iyi sonuç verdiği tespit edilmiştir. Bütün otolit ve kesit otolit yöntemlerinden birinin tercih edilmesi gerektiği durumlarda ise bütün otolitin kullanılabileceği sonucuna ulaşılmıştır. Kesit otolit yönteminin küçük yaş örnekleminde zaman ve maliyet açısından kayba yol açtı̆̆ı düşünülmektedir.

Yaş dağılımı sonuçları ele alındığında Tatlısu Levreği populasyonunun genellikle genç bireylerden oluştuğu görülmektedir. Populasyon geneline bakıldığında en küçük birey 0 yaşındaki bireylerdir. Bu durumun örneklemede kullanılan avcıllk yönteminden ve örnekleme zamanından kaynaklanabileceği düşünülmektedir. Yedikır Baraj Gölü’nde yaşayan Tatlısu Levreği populasyonun yaş tayini için kullanılan omur ve otolit yöntemlerinin karşılaştırmalı analizi üzerine ilk kapsamlı 
çalışması olması sebebiyle mevcut araştırmanın tür ile ilgili yapılacak sonraki çalışmalara kaynak teşkil etmesi beklenmektedir.

\section{Teșekkür}

Bu çalışma Canan ŞİMŞEK'in Yüksek Lisans tezinden üretilmiştir. Yüksek Lisans tezinin bir bölümünü içeren bu çalışma 29.10.2018-01.11.2018 tarihlerinde Afyonkarahisar’ da düzenlenen “ ‘5. Ulusal Su Kongresi-2. Uluslararası Su Günleri’nde’’ sözlü olarak sunulmuştur.

\section{Yazarların Katkısı}

Tüm yazarlar çalışmaya eşit katkıda bulunmuştur.

\section{Çıkar Çatışması Beyanı}

Yazarlar arasında herhangi bir çıkar çatışması bulunmamaktadır.

\section{Araştırma ve Yayın Etiği Beyanı}

Yapılan çalışmada araştırma ve yayın etiğine uyulmuştur.

\section{Kaynaklar}

Anonim, (2018). Amasya İl Kültür ve Turizm Müdürlüğü, http://www.amasyakulturturizm.gov.tr/TR,59553/yedikugular-kus-cenneti.html (Erişim tarihi: 16.05.2018)

Baker, T. T., and Timmons, L. S. (1991). Precision of ages estimated from five bony structures of Arctic Char (Salvelinus alpinus) from the Wood River System, Alaska. Canadian Journal of Fisheries and Aquatic Sciences, 48(6), 1007-1014.

Banda, F. (2014). A Comparative analysis of Perca fluviatilis population dynamics from two Lakes in New Zealand (Master Thesis). New Zealand: Auckland University of Technology, Auckland.

Beamish, R. J., and Fournier, D. A. (1981). A method for comparing the precision of a set of age determinations. Canadian Journal of Fisheries and Aquatic Sciences, 38, 982-983.

Beğburs, C. R. (2010, June). Investigation of growth features of perch (Perca fluviatilis L. 1758) population in Ürkmez Dam Lake (Izmir-Turkey). 2nd International Symposium on Sustainable Develeopment (pp. 693-699). Sarajevo, Bosnia.

Ceccuzzi, P., Terova, G., Brambilla, F., Antonini, M., and Saroglia, M. (2011). Growth, diet, and reproduction of European perch Perca fluviatilis L. in Lake Varese, Northwestern Italy. Fisheries Science, 77(4), 533-545.

Ceyhan, T., ve Akyol, O. (2006). Marmara Denizi lüfer (Pomatomus saltatrix L., 1766) balıklarının yaş dağılımı ve çatal boy-otolit boyu arasındaki ilişki. Ege Üniversitesi Su Ürünleri Dergisi, 23(1-3), 369372.

Chang, W. Y. B. (1982). A statistical method for evaluating the reproducibility of age determination. Canadian Journal of Fisheries and Aquatic Sciences, 39(8), 1208-1210.

Craig, J. F. (2000). Percid fishes, systematic, ecology and exploitation. Oxford: Blackwell Science. 
Das, M. (1994). Age determination and longevity in fishes. Gerontology, 40(2-4), 70-96.

Dwyer, K. S., Walsh, S. J., and Campana, S. E. (2003). Age determination, validation and growth of Grand Bank yellowtail flounder (Limanda ferruginea). International Council for the Exploration of the Sea Journal of Marine Science, 60(5), 1123-1138.

Heibo, E., and Magnhagen, C. (2005). Variation in age and size at maturity in perch (Perca fluviatilis L.), compared across lakes with different predation risk. Ecology Freshwater Fish, 14(4), 344-351.

Holmgren, K., and Appelberg, M. (2001). Effects of environmental factors on size related growth efficiency of perch, Perca fluviatilis. Ecology of Freshwater Fish, 10(4), 247-256.

Jatmiko, I., Haddy, J., and Williams, M. (2013). Comparison of age estimates from various hard parts for redfin perch, Perca fluviatilis, In Tasmania. Indonesian Fisheries Research Journal, 19(1), 47-54.

Jellyman, D. J. (1980). Age, growth and reproduction of perch, Perca fluviatilis L., in Lake Pounui. New Zealand Journal of Marine \& Freshwater Research, 14(4), 391-400.

Karataş, M. (2010). Balık Biyolojisi Araştırma Yöntemleri. Ankara: Öncü Basımevi Nobel Yayın No:4.

Linløkken, A., Kleiven, E., and Matzow, D. (1991). Population structure, growth and fecundity of perch (Perca fluviatilis L.) in an acidified river system in Southern Norway. Hydrobiologia, 220(3), 179-188.

Linløkken, A., and Seeland, P. A. H. (1996). Growth and production of perch (Perca fluviatilis L.) responding to biomass removal. Annales Zoologici Fennici, 33, 427-435.

Maraşlığlu, F. (2007). Yedikır Baraj Gölü (Amasya-Türkiye) fitoplanktonu ve mevsimsel değişimi üzerine bir araştırma. Doktora Tezi, Ondokuz Mayıs Üniversitesi, Fen Bilimleri Enstitüsü, Samsun.

Olin, M., Vinni, M., Lehtonen, H., Rask, M., Ruuhijärvi, J., Saulamo, K., and Ala-Opas, P. (2010). Environmental factors regulate the effects of roach Rutilus rutilus and pike Esox lucius on perch Perca fluviatilis population in small boreal borest lakes. Journal of Fish Biology, 76(6), 1277-1293.

Polat, N., Bostanc1, D., and Y1lmaz, S. (2004). Age analysis on different bony structures of perch (Perca fluviatilis L. 1758) inhabiting Derbent Dam Lake (Bafra, Samsun). Turkish Journal of Veterinary and Animal Sciences, 28(3), 465-469.

Sarvala, J., and Helminen, H. (1996). Year-class fluctuations of perch (Perca fluviatilis) in Lake Pyhäjärvi, Southwest Finland. Annales Zoologici Fennici, 33, 389-396.

Saygın, S. (2013). Ladik Gölü (Samsun, Türkiye) 'ndeki tatllsu levreği (Perca fluviatilis L., 1758) 'nde güvenilir yaş tayini ve büyüme özellikleri. Yüksek Lisans Tezi, Ondokuz Mayıs Üniversitesi, Fen Bilimleri Enstitüsü, Samsun.

Saygın, S., Yılmaz, S., Yazıcıoğlu, O., and Polat, N. (2015). Comparative age determination from different bony structures of perch (Perca fluviatilis Linnaeus, 1758) in Lake Ladik (Samsun/Turkey). Biological Diversity and Conservation, 8(1), 21-27.

Secor, D. H., Dean, J. M., and Laban, E. H. (1992). Otolith removal and preparation for microstructural examination. Otolith microstructural examination and analysis. Canadian Special Publication of Fisheries and Aquatic Sciences, 117, 19-57.

Thorpe, J. E. (1977). Morphology, physiology, behaviour and ecology of Perca fluviatilis L. and Perca flavescens Mitchill. Journal of The Fisheries Research Board of Canada, 34(10), 1504-1514.

Troynikov, V. S., Gorfine, H.K., Ložys, L., Pūtys, Z., Jakubavičiūtè, E., and Day, R. W. (2011). Parameterization of European perch Perca fluviatilis length-at-age data using stochastic Gompertz Growth Models. Journal of Fish Biology, 79(7), 1940-1949.

Tyler, A. V., Beamish, R. J., and McFarlane, G. A. (1989). Implications of age determination errors to yield estimates. Effects of ocean variability on 84 recruitment and an evaluation of parameters used in stock assessment models. Canadian Special Publication of Fisheries and Aquatic Sciences, 108, 27-35.

Yılmaz, S. (2006). Samsun ili tatlı sularında yaşayan bazı ekonomik balık populasyonlarında yaş belirleme. Doktora Tezi, Ondokuz Mayıs Üniversitesi, Fen Bilimleri Enstitüsü, Samsun. 